Keywords: $A R P, S W P F, I S D P$

Retention: Permanent

\title{
Investigation of Plutonium and Uranium Uptake into MCU Solvent and Next Generation Solvent
}

T. B. Peters

S. D. Fink

January 2012

Savannah River National Laboratory

Savannah River Nuclear Solutions

Aiken, SC 29808

Prepared for the U.S. Department of Energy under contract number DE-AC09-08SR22470. 
SRNL-STI-2011-00746

Revision 0

\section{DISCLAIMER}

This work was prepared under an agreement with and funded by the U.S. Government. Neither the U.S. Government or its employees, nor any of its contractors, subcontractors or their employees, makes any express or implied:

1. warranty or assumes any legal liability for the accuracy, completeness, or for the use or results of such use of any information, product, or process disclosed; or

2. representation that such use or results of such use would not infringe privately owned rights; or

3. endorsement or recommendation of any specifically identified commercial product, process, or service.

Any views and opinions of authors expressed in this work do not necessarily state or reflect those of the United States Government, or its contractors, or subcontractors.

\section{Printed in the United States of America}

Prepared for

U.S. Department of Energy 


\section{REVIEWS AND APPROVALS}

\section{AUTHORS:}

T. B. Peters, Author, SRNL/SASP

Date

TECHNICAL REVIEW:

R. A. Pierce, Technical Reviewer, SRNL/SASP

Date

APPROVAL:

S. D. Fink, SRNL/SASP, Manager

Date

S. L. Marra, SRNL/E\&CPT Research Programs, Manager

Date

B.A. Oard, Manager, MCU Life Extension/NGS

Date 


\section{EXECUTIVE SUMMARY}

At the request of the Savannah River Remediation (SRR) customer, the Savannah River National Laboratory (SRNL) examined the plutonium (Pu) and uranium (U) uptake into the Next Generation Solvent (NGS) that will be used at the Salt Waste Processing Facility (SWPF). SRNL examined archived samples of solvent used in Extraction-ScrubStrip (ESS) tests, as well as samples from new tests designed explicitly to examine the $\mathrm{Pu}$ and U uptake.

Direct radiocounting for $\mathrm{Pu}$ and $\mathrm{U}$ provided the best results. Using the radiocounting results, we found that in all cases there were $<3.41 \mathrm{E}-12 \mathrm{~g}$ Pu/g of NGS and $<1.17 \mathrm{E}-05 \mathrm{~g}$ U/g of NGS in multiple samples, even after extended contact times and high aqueous:organic volume phase ratios.

These values are conservative as they do not allow for release or removal of the actinides by scrub, strip, or solvent wash processes. The values do not account for extended use or any increase that may occur due to radiolytic damage of the solvent. 


\title{
LIST OF ABBREVIATIONS
}

\author{
CSSX - Caustic-Side Solvent Extraction \\ DSS - Decontaminated Salt Solution \\ ESS - extraction-scrub-strip \\ HEU - highly enriched uranium \\ ISDP - Integrated Salt Disposition Project \\ MCU - Modular Caustic-side Solvent Extraction Unit \\ NCSE - Nuclear Criticality Safety Evaluation \\ NGS - Next Generation Solvent \\ ORNL - Oak Ridge National Laboratory \\ PuTTa - Plutonium Thenoyltrifluoroacetone \\ SRNL - Savannah River National Laboratory \\ SRR - Savannah River Remediation \\ SSFT - Salt Solution Feed Tank \\ SSRT - Salt Solution Receipt Tank
}




\subsection{Introduction}

The Modular Caustic Side Solvent Extraction Unit (MCU) uses the Caustic-Side Solvent Extraction (CSSX) process to remove cesium (Cs) from alkaline waste. This process involves the use of an organic extractant, BoBCalixC6, ${ }^{\mathrm{r}}$ in an organic matrix to selectively remove $\mathrm{Cs}$ from the caustic waste. The organic solvent mixture flows counter-current to the caustic aqueous waste stream through the use of centrifugal contactors. After extracting the Cs, the loaded solvent is stripped of Cs by contact with dilute nitric acid $\left(\mathrm{HNO}_{3}\right)$ and the $\mathrm{Cs}$ concentrate is transferred to the Defense Waste Processing Facility (DWPF), while the organic solvent is cleaned and recycled for further use. As of September 2011, MCU had processed three macrobatches of tank waste, and started processing a fourth macrobatch of material.

The Office of Waste Processing (EM-31) expressed an interest in investigating the further optimization of the organic solvent by replacing the BoBCalixC6 extractant with a more efficient extractant, a next generation CSSX solvent (NGS). ${ }^{1}$ This replacement should yield dividends in improved Cs removal from the caustic waste stream, and higher caustic waste processing rates. To that end, EM-31 provided funding for both the Savannah River National Laboratory (SRNL) and the Oak Ridge National Laboratory (ORNL). SRNL wrote a Task Technical Quality and Assurance Plan (TTQAP) for this work. ${ }^{2}$

Recently, SRR expressed concern that the affinity of NGS to extract and retain U and/or $\mathrm{Pu}$ is unknown, and this data is needed for safety calculations, in particular for the Nuclear Criticality Safety Evaluation (NCSE) revision. SRR needs this information for the Nuclear Criticality Safety Evaluation (NCSE) revision. The NCSE evaluates the possibility of criticality accidents in the Salt Solution Receipt Tank (SSRT) and Salt Solution Feed Tank (SSFT). The scenario postulates the presence of solvent in the SSRT or SSFT due to an unforeseen upset and extraction of fissile material into the solvent. The NCSE also evaluates the possibility of a criticality accident in the Decontaminated Salt Solution (DSS) decanter. The accident scenario postulates the decanter contains solvent that has extracted fissile material.

SRNL was tasked with assessing the affinity of the NGS for U and Pu after contacting salt solutions.

\subsection{Experimental Procedure}

For this work, SRNL took two paths. First, the archived organic phases from three previous Extraction-Scrub-Strip (ESS) tests were analyzed for Pu and U content. Second, two sets of contact tests were performed using two different aqueous simulants. In each

\footnotetext{
${ }^{\Upsilon}$ BoBCalixC6 stands for calix[4] arene-bis-(tert-octylbenzo)-crown-6
} 
set of contact tests, one portion of the aqueous phase was contacted with the current solvent, and another portion of the aqueous phase was contacted with NGS.

\subsection{Analysis of Prior ESS Samples}

Archived samples from three previous ESS tests were analyzed for Pu content via Plutonium Thenoyltrifluoroacetone (PuTTa). The samples sent forward are identified as Tests "F”, "G” and "H" and the results from those ESS tests were previously reported., 3,4,5

\subsection{Solvent Preparation for Contact Tests}

ORNL provided the recipe for the NGS. ${ }^{6}$ SRNL prepared a $250-\mathrm{mL}$ batch of this solvent after ordering the individual components. ${ }^{\perp}$ The extractant ${ }^{\Sigma}$ and Modifier ${ }^{f}$ were obtained from Marshallton Research Laboratories. The Isopar $L{ }^{\circledR}$ was purchased from ExxonMobil. A sample of the suppressor ${ }^{\Re}$ was donated by Cognis.

The recipe for the new solvent formulation is given in Table 1. The prepared solvent had a calculated density of $0.835 \mathrm{~g} / \mathrm{mL}$. For the current solvent, material from batch S2D1-YESBOB-T-WI was used.

Table 1. Material Additions for the Improved Solvent

\begin{tabular}{|c|c|}
\hline Chemical & Added Mass (g) \\
\hline MAXCalix & 11.95 \\
\hline Modifier & 42.30 \\
\hline Suppressor & 0.310 \\
\hline Isopar L TM & 154.1 \\
\hline
\end{tabular}

\subsection{Simulant Feed Makeup and Compositions}

A previously prepared spiked waste simulant was used in the first set of contact tests. This material is identified as "SWS-9-2007" and its composition is listed in Table 2.

While the simulant does not precisely match the composition of the waste in Tank $49 \mathrm{H}$, this was not the goal. The requirements for the contact tests were that the material approximate the type of caustic salt solution that the solvent would contact in actual use, and have a reasonable concentration of $\mathrm{Pu}$ and $\mathrm{U}$ present.

\footnotetext{
${ }^{\perp}$ The prepared solvent was from preparation\#2, 12/14/2010.

${ }^{\Sigma}$ The extractant, MAXCalix, stands for 1,3-alt-25,27-Bis(3,7-dimethyloctyloxy)calix[4]arenebenzocrown-6

${ }^{f}$ Modifier stands for_1-(2,2,3,3,-Tetrafluoropropoxy)-3-(4-sec-butylphenoxy)-2-propanol

${ }^{\Re}$ The suppressor is a derivitized guanidine, N, N'-cyclohexyl, N''-tridecyl guanidine

* This batch of solvent was originally prepared with no extractant as S2-NOBOB-T-WI (see WSRC-NB-2005-00060).

The extractant was added later on (see WSRC-NB-2007-00054).
} 
Table 2. Composition of SWS-9-2007

\begin{tabular}{|c|c|c|c|}
\hline Analyte & Concentration & Analyte & Concentration \\
\hline Free $\mathrm{OH}$ & $1.37 \mathrm{M}$ & Total Na & $5.05 \mathrm{M}$ \\
\hline $\mathrm{NO}_{3}{ }^{-}$ & $2.13 \mathrm{M}$ & ${ }^{85} \mathrm{Sr}$ & $3.00 \mathrm{E}+04 \mathrm{dpm} / \mathrm{mL}$ \\
\hline $\mathrm{Al}(\mathrm{OH})_{4}^{-}$ & $0.404 \mathrm{M}$ & ${ }^{137} \mathrm{Cs}$ & $9.63 \mathrm{E}+04 \mathrm{dpm} / \mathrm{mL}$ \\
\hline $\mathrm{NO}_{2}{ }^{-}$ & $0.133 \mathrm{M}$ & ${ }^{239 / 40} \mathrm{Pu}$ & $220 \mu \mathrm{g} / \mathrm{L}$ \\
\hline $\mathrm{SO}_{4}{ }^{2-}$ & $0.483 \mathrm{M}$ & ${ }^{237} \mathrm{~Np}$ & $461 \mu \mathrm{g} / \mathrm{L}$ \\
\hline $\mathrm{CO}_{3}{ }^{2-}$ & $0.0298 \mathrm{M}$ & ${ }^{238} \mathrm{U}$ & $10,700 \mu \mathrm{g} / \mathrm{L}$ \\
\hline
\end{tabular}

Results from the first contact test showed that we needed a new simulant with no beta/gamma emitters so that lower detection limits for the actinides could be obtained. For the second set of contact test, SRNL used a similar aqueous phase ("SWS-8-2007"), with the notable exception being that the only radionuclides present were ${ }^{238} U$ and ${ }^{235} U$.

Table 3. Composition of SWS-8-2007

\begin{tabular}{|c|c|c|c|}
\hline Analyte & Concentration & Analyte & Concentration \\
\hline Free OH & $1.38 \mathrm{M}$ & $\mathrm{SO}_{4}{ }^{2-}$ & $0.606 \mathrm{M}$ \\
\hline $\mathrm{NO}_{3}{ }^{-}$ & $3.11 \mathrm{M}$ & $\mathrm{CO}_{3}{ }^{2-}$ & $0.0314 \mathrm{M}$ \\
\hline $\mathrm{Al}(\mathrm{OH})_{4}^{-}$ & $0.461 \mathrm{M}$ & $T^{-}$ & $5.60 \mathrm{M}$ \\
\hline $\mathrm{NO}_{2}{ }^{-}$ & $0.160 \mathrm{M}$ & ${ }^{235} \mathrm{U}$ & $8.32 \mathrm{mg} / \mathrm{L}(39.9 \mathrm{dpm} / \mathrm{mL})$ \\
\hline
\end{tabular}

The analytical uncertainty is $10 \%$ for all measurements except for the $\mathrm{U}$, which is $6.62 \%$.

In the case of the uranium, the simulant was prepared with depleted uranium (DU). After the initial preparation, a spike of $60 \%{ }^{235} \mathrm{U}$ mass highly enriched uranium (HEU) was added to generate a final simulant with a high value of ${ }^{235} U$. This solution was then filtered through a $0.45 \mu \mathrm{m}$ filter cup to ensure that the only $\mathrm{U}$ in solution was in a soluble form. While the initial value of the ${ }^{238} \mathrm{U}$ is known, after the spike of HEU, the ${ }^{238} \mathrm{U}$ was neither tracked nor analyzed.

\subsection{Contact Testing}

In each contact test, the same procedure was followed. Either 30 or $100 \mathrm{~mL}$ of the aqueous phase was placed in a Teflon ${ }^{\mathrm{TM}}$ separatory funnel. Researchers then added an amount of fresh, unused solvent equal to $1 / 10^{\text {th }}$ the volume of the aqueous phase. The contents of the funnel were hand mixed with medium agitation for 2 minutes. The funnel was then allowed to sit for an equilibrium time of one week. At that point samples were taken of one phase or another, and sent for analysis. Pu analysis was via PuTTa. Uranium analysis was via gamma radiocounting. 


\subsection{Results and Discussion}

\subsection{Results from Old Sample Analyses}

The archived "F", "G" and "H" samples were analyzed for Pu content by PuTTa. As this is a direct-counting method, no additional sample preparation was required beyond the normal analytical method. The results of the analyses are shown in Table 4, along with the calculated D-value. The D-value is calculated by dividing the sample (organic) result by the aqueous feed value (which varied from sample to sample). In all cases, the very low detection limits gave very low D-values. ${ }^{238} \mathrm{Pu}$ was used as opposed to ${ }^{239 / 240} \mathrm{Pu}$ as the latter gave less-than detectable results in both the samples and in the feed materials.

Table 4. PuTTa Results from the Archived Samples

\begin{tabular}{|c|c|c|c|c|}
\hline Sample ID & Solvent & ${ }^{238} \mathbf{P u}(\mathbf{d p m} / \mathbf{m L})$ & D-value & gPu/gNGS \\
\hline F & NGS & $<3.14$ & $<0.000276$ & $<1.73 \mathrm{E}-12$ \\
\hline G & NGS & $<6.18$ & $<0.000206$ & $<3.41 \mathrm{E}-12$ \\
\hline H & current & $<5.23$ & $<0.000175$ & $<2.88 \mathrm{E}-12$ \\
\hline
\end{tabular}

Although not using the same exact experimental procedure, previous work at $\mathrm{ORNL}^{7}$ gave a Pu D-value of $1.6 \mathrm{E}-04$ for tests involving the current BobCalix solvent formulation, which is comparable to the values in Table 4. The gPu/g NGS is calculated by dividing the mass of Pu in a $1 \mathrm{~mL}$ sample of the analyzed NGS by the mass of the extractant in $1 \mathrm{~mL}$ of NGS.

\subsection{Results from Contact Tests}

The first test failed to give reliable results due to higher than desired detection limits. SRNL performed a second contact test using a different simulant. The new simulant omitted beta/gamma emitters that interfere with the weak ${ }^{235} \mathrm{U}$ signal. The SWS-8-2007 simulant was chosen, and a portion of this material was spiked with HEU to increase the ${ }^{235} \mathrm{U}$ content. Table 5 contains the analytical results after the contact test.

Table 5. ${ }^{235} \mathrm{U}$ Results from the Second Contact Test

\begin{tabular}{|c|c|c|c|c|c|}
\hline Sample ID & Solvent & Phase & $\begin{array}{c}{ }^{235} \mathbf{U} \\
(\mathbf{d p m} / \mathbf{m L})\end{array}$ & D-value & gU/gNGS \\
\hline MAX_SWS_8_2007_contact & NGS & solvent & $<2.68$ & $<0.0672$ & $<1.17 \mathrm{E}-05$ \\
\hline
\end{tabular}

The D-value is calculated by dividing the sample (organic) result by the aqueous feed value (39.9 dpm/mL - see Table 3). Even in a low background, the weak activity of ${ }^{235} \mathrm{U}$ 
makes it difficult to count to lower values. A lower detection limit may be possible by going to more expensive counting isotopes and longer counting times.

The gU/g NGS is calculated by dividing the mass of $\mathrm{U}$ in a 1-mL sample of the analyzed NGS by the mass of the extractant in $1 \mathrm{~mL}$ of NGS.

\subsection{Conclusions}

Analyses indicated that the NGS does not uptake either Pu or U within the analytical detection limits. This result is despite an extended contact time (1 week) with no scrubbing, stripping, or washing cycles and a high aqueous:organic volume phase ratio (10:1). The conditions of these tests are conservative compared to the actual operating conditions at the MCU. 
SRNL-STI-2011-00746

Revision 0

\subsection{References}

${ }^{1}$ Project\# HQTD1002, WP-2.1.6, "Next Generation Cesium Solvent"

${ }^{2}$ T. B. Peters and S. D. Fink, "Task Technical and Quality Assurance Plan For Studies of Improved CSSX Solvent Formulations”, SRNL-RP-2010-01028, Rev 1, August 2010.

${ }^{3}$ T. B. Peters, S. D. Fink, "Results of the Third Extraction-Scrub-Strip Real Waste Test Using an Improved Solvent Formulation”, SRNL-STI-2010-00803, Rev.0, March 2011.

${ }^{4}$ T. B. Peters, R. A. Pierce, F. F. Fonduer, S. D. Fink, "Small Scale Performance Testing of the NextGeneration CSSX Solvent with Actual SRS Tank Waste”, SRNL-STI-2011-00631, October 27, 2011.

${ }^{5}$ T. B. Peters, A. L. Washington II, F. F. Fondeur, S. D. Fink, "Solvent Hold Tank Sample Results for MCU-11-314, MCU-11-315, MCU-11-316, MCU-11-317, MCU-11-318 and MCU-11-319”, SRNL-STI2011-00301, Rev.0, June 2011.

${ }^{6}$ B. A. Moyer, “Initial NG-CSSX Solvent Recommendation,” letter to N. P. Machara, June 30, 2010.

${ }^{7}$ B. A. Moyer, S. D. Alexandratos, P. V. Bonnesen, G. M. Brown, J. E. Caton Jr., L. H. Delmau, C. R. Duchemin, T. J. Haverlock, T. G. Levitskaia, M. P. Maskarinec, F. V. Sloop, Jr., C. L. Stine, "CausticSided Solvent Extraction and Physical Properites Progress in FY2000 and FY2001”, ORNL/TM-2001/285, February, 2002. 


\section{Distribution:}
A. B. Barnes, 999-W
S. D. Fink, 773-A
B. J. Giddings, 786-5A
C. C. Herman, 999-W
S. L. Marra, 773-A
F. M. Pennebaker, 773-42A
J. C. Griffin, 773-A
A. P. Fellinger, 773-41A
W. R. Wilmarth, 773-A
E. J. Freed, 704-56H
D. J. Martin, 241-152H
M. W. Geeting, 241-152H
B. A. Gifford, 704-56H
M.T. Keefer, 241-156H
M. T. Hubbard, 704-20S
S. G. Campbell, 992-5W
T.B. Peters, 773-42A
C. A. Nash, 773-42A
M. R. Poirier, 773-42A
F. F. Fondeur, 773-A
R. A. Pierce, 773-A
A. L. Washington, 773-42A
N. P. Machara
R. E. Edwards, 773-67A
B. A. Oard, $241-197 \mathrm{H}$
A. Samadi, 241-197H
S. McLeskey, 241-152H
W. B. Brasel, 992-2W
C. Conner, Parsons
R. D. Lentsch, Parsons
M. S. Brugh, Parsons
T. D. Burns, Parsons
A. N. Singer, Parsons
M. J. Thomas, Parsons
R. J. Schepens, Parsons
R. K. Leugemors, 992-5W
P. G. Suggs, 704-S
P. Jackson, 703-46A
B. A. Moyer, ORNL
L. H. Delmau, ORNL 